\title{
H2 Optimal and $\mu$-synthesis Design of Quarter Car Active Suspension System
}

\author{
Mustefa Jibril \\ Department of Electrical \& Computer Engineering, Dire Dawa Institute of Technology, Dire Dawa, Ethiopia \\ Eliyas Alemayehu Tadese \\ Faculty of Electrical \& Computer Engineering, Jimma Institute of Technology Jimma, Ethiopia
}

\begin{abstract}
Better journey comfort and controllability of automobile are pursued via car industries with the aid of considering using suspension system which plays a very crucial function in handling and ride comfort characteristics. This paper presents the design of an active suspension of quarter automobile system using robust $\mathrm{H} 2$ optimal controller and robust $\mu$ - synthesis controller with a second order hydraulic actuator. Parametric uncertainties have been additionally considered to model within the system. Numerical simulation become completed to the designed controllers. Results display that during spite of introducing uncertainties, the designed $\mu$ - synthesis controller improves ride consolation and road protecting of the automobile while as compared to the $\mathrm{H} 2$ optimal controller. Index Terms--- Quarter car active suspension system, $\mathrm{H} 2$ optimal controller, $\mu$ - synthesis controller
\end{abstract}

DOI: $10.7176 / \mathrm{CTI} / 10-03$

Publication date:July $31^{\text {st }} 2020$

\section{Introduction}

An automobile suspension system is the mechanism that bodily separates the automobile body from the wheels of the car. The cause of suspension system is to enhance the experience comfort, road handling and stability of automobiles. Apple backyard and Well stead have proposed several performance traits to be taken into consideration so one can obtain an excellent suspension system. Suspension includes the system of springs, shock absorbers and linkages that connects a vehicle to its wheels. In other that means, suspension system is a mechanism that bodily separates the car body from the automobile wheel. The principal feature of automobile suspension system is to limit the vertical acceleration transmitted to the passenger which directly affords road consolation.

The fundamental idea of land vehicle transportation has not modified tons inside the previous few many years, although a great deal progress become made in enhancing and optimizing automobile design and era. The quest to continually go quicker, similarly and extra effortlessly, has lead in latest years to the improvement of advanced suspension structures. A progressed suspension system allows a vehicle to attain better speeds over rougher terrain, and results in better handling, in addition to improved trip consolation.

A first step in vehicle suspension design is estimating a preferred spring and damper function, and verifying that characteristic the use of software program simulation. The models used at some point of this step are generally low-order, simple fashions, which hampers short development progress. To predict car response before automobile prototype finishing touch, many researchers have tried to use complex and superior damper fashions to simulate the car's dynamics, however these fashions all be afflicted by a few disadvantage - it's far both based on empirical statistics, giving no indication of the bodily parameters of the design sought; it could be overly complex, having many parameters and accordingly rendering software impractical; or it can be quick however based totally on the idea that there's no hysteresis in the damping character.

\section{Mathematical Models}

\subsection{Active Suspension System Mathematical Model}

The quarter car active suspension system model is shown in Figure 1. 


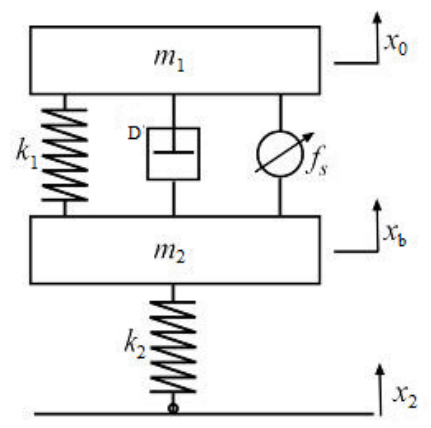

Figure 1: Quarter model of active suspension system.

The quarter car active suspension system mathematical model for a two degrees of freedom motion differential equations will be as follow:

$m_{1} \ddot{x}_{0}(t)+D\left[\dot{x}_{0}(t)-\dot{x}_{2}(t)\right]+k_{1}\left[x_{0}(t)-x_{2}(t)\right]=u \quad(1) m_{2} \ddot{x}_{2}(t)-D\left[\dot{x}_{0}(t)-\dot{x}_{2}(t)\right]+k_{1}\left[x_{2}(t)-x_{0}(t)\right]+k_{2}\left[x_{2}(t)-x_{1}(t)\right]=-u$

\section{Road Profiles}

\subsection{Random Road Profile}

The random road disturbance input has a maximum peak of $15 \mathrm{~cm}$ and minimum peak of $-15 \mathrm{~cm}$ as shown in Figure 2.

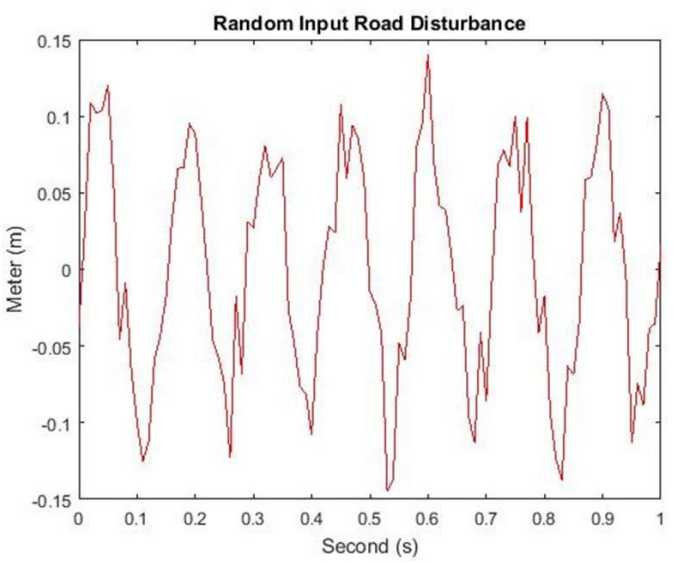

Figure 2: Random road profile

\section{The Proposed Controller Design}

The active suspension system with $\mathrm{H} 2$ optimal and $\mu$-synthesis controllers with a second order hydraulic actuator system block diagram is shown in Figure 3.

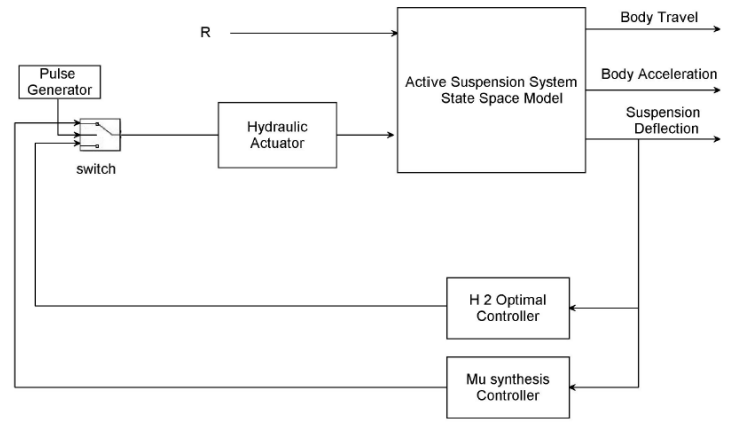

Figure 3: Active suspension system with $\mathrm{H} 2$ optimal and $\mu$ - synthesis controller's system block diagram The switching system switch in micro seconds. The hydraulic actuator model is a second order transfer function defined as:

$$
\text { actuator }=\frac{4 s+23}{s^{2}+26 s+14}
$$




\section{Result and Discussion}

The quarter car active suspension system parameter values are shown in Table 1.

Table 1: Parameters of quarter vehicle model

\begin{tabular}{|l|l|l|}
\hline Model parameters & symbol & symbol Values \\
\hline Vehicle body mass & $\mathrm{m} 1$ & $4550 \mathrm{Kg}$ \\
\hline Wheel assembly mass & $\mathrm{m} 2$ & $63 \mathrm{Kg}$ \\
\hline Suspension stiffness & $\mathrm{k} 1$ & $18,500 \mathrm{~N} / \mathrm{m}$ \\
\hline Tire stiffness & $\mathrm{k} 2$ & $165,000 \mathrm{~N} / \mathrm{m}$ \\
\hline Suspension damping & $\mathrm{D}$ & $800 \mathrm{~N}-\mathrm{s} / \mathrm{m}$ \\
\hline
\end{tabular}

\subsection{Control Targets Output Specifications}

The control targets output specifications of the quarter car active suspension system is shown in Table 2 below. Table 2. Control targets output specifications

\begin{tabular}{|l|l|l|}
\hline No & Control Targets & Output \\
\hline 1 & Body travel & Minimum \\
\hline 2 & Body acceleration & Minimum \\
\hline 3 & Suspension deflection & Same as Road Profile \\
\hline
\end{tabular}

\subsection{Simulation of a Random Road Disturbance}

The body travel, body acceleration and suspension deflection simulation output is shown in Figure 4, Figure 5 and Figure 6 respectively.

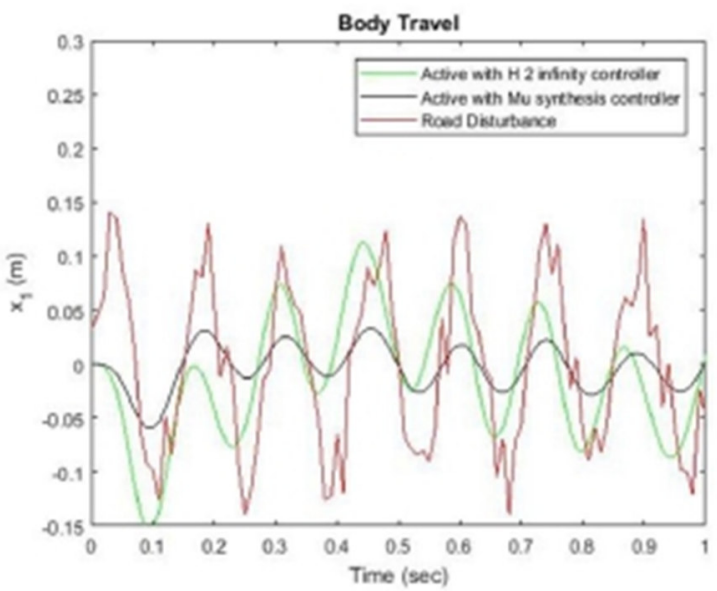

Figure 4: Body travel for random road disturbance

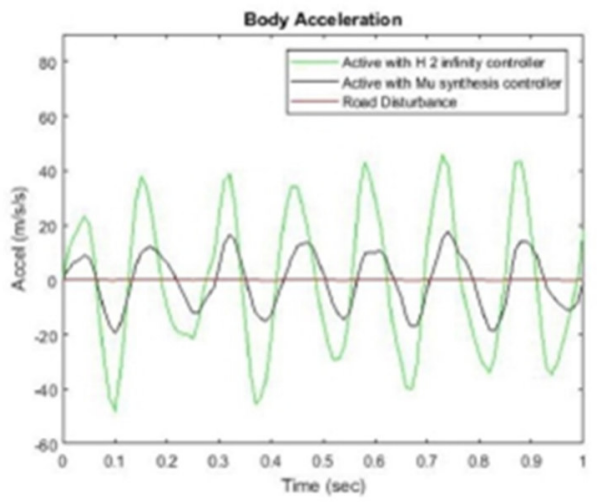

Figure 5: Body acceleration for random road disturbance 


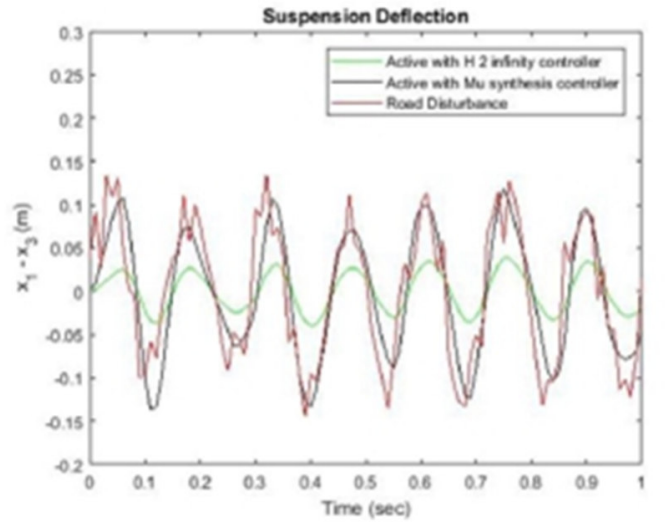

Figure 6: Suspension deflection for random road disturbance

\subsection{Numerical Values of the Simulation Outputs}

The numerical values of the simulation output for the control targets body travel, body acceleration and suspension deflection is shown in Table 3, Table 4 and Table 5 bellow.

Table 3: Numerical values of the body travel simulation output

\begin{tabular}{|l|l|l|}
\hline No & Systems & Random \\
\hline 1 & Road Profile & $0.15 \mathrm{~m}$ \\
\hline 2 & H2 Optimal & $0.04 \mathrm{~m}$ \\
\hline 3 & $\mu$ - synthesis & $0.01 \mathrm{~m}$ \\
\hline
\end{tabular}

Table 2 shows us the active suspension system with $\mu$ - synthesis controller have the minimum body travel amplitude in the random road profile.

Table 3: Numerical values of the body acceleration simulation output

\begin{tabular}{|l|l|l|}
\hline No & Systems & Random \\
\hline 1 & Road Profile & $5 \frac{m}{s^{2}}$ \\
\hline 2 & H2 Optimal & $40 \frac{m}{s^{2}}$ \\
\hline 3 & $\mu$ - synthesis & $20 \frac{m}{s^{2}}$ \\
\hline
\end{tabular}

Table 3 shows us the active suspension system with $\mu$-synthesis controller have the minimum body acceleration amplitude in the random road profile.

Table 4: Numerical values of the suspension deflection simulation output

\begin{tabular}{|l|l|l|}
\hline No & Systems & Random \\
\hline 1 & Road Profile & $0.14 \mathrm{~m}$ \\
\hline 2 & H2 Optimal & $0.04 \mathrm{~m}$ \\
\hline 3 & $\mu$ - synthesis & $0.14 \mathrm{~m}$ \\
\hline
\end{tabular}

Table 4 shows us the active suspension system with $\mu$ - synthesis controller have the suspension deflection amplitude the same as the road profile input in the random road profiles.

\section{Conclusion}

The technique turned into advanced to design an active suspension for a passenger vehicle with the aid of designing a controller, which improves overall performance of the system with respect to design desires compared to active suspension system. Mathematical modeling has been accomplished using a two degree-of-freedom model of the quarter vehicle model for active suspension system considering best vertical movement to evaluate the overall performance of suspension with recognize to various contradicting design goals. H2 optimal and mu-synthesis 
controllers design method has been tested for the active suspension system using random road profile. The capability for advanced experience comfort and better road managing using H2 optimal and mu-synthesis controllers design is examined. The objectives of this undertaking were achieved. Dynamic model for linear quarter car active suspension systems has been formulated and derived for the 2 types of the proposed controllers. The two proposed controllers are compared and the simulation consequences prove the effectiveness of the provided active suspension system with mu synthesis controller.

\section{References}

[1]. Pusadkar et al. "Linear Disturbance Observer Based Sliding Mode Control for Active Suspension Systems with Non-ideal actuator" Journal of Sound and Vibration, p 428-444, 2019.

[2]. Jianjun Meng et al. "Robust Non Fragile H infinity Control of Lateral Semi-active Suspension of Rail Vehicles" Journal of Discrete Dynamics in Nature and Society, p 1-12, 2019.

[3]. Chen.X et al. "Robust $\mathrm{H}$ infinity Control Design of an Electromagnetic Actuated Active Suspension Considering the Structure Nonlinearity" Journal of Automobile Engineering, 2018.

[4]. Kuiyang Wang et al. "Static Output Feedback H infinity Control for Active Suspension System with Input Delay and Parameter Uncertainty” Journal of Advances in Mechanical Engineering, 10(7), 2018.

[5]. Pang.H "Adaptive Back Stepping Based Tracking Control Design for Nonlinear Active Suspension System with Parameter Uncertainty and Safety Constraints" ISA Transactions, 2018.

[6]. Pan.H et al."Robust Finite-time Tracking Control for Nonlinear Suspension Systems via Disturbance Compensation” Mechanical System Signal Processing, p 49-61, 2017.

[7]. Yusuf Altun et.al "The Road Disturbance Attenuation for Quarter Car Active Suspension System via a New Static Two Degree of Freedom Design" An International Journal of Optimization and Control: Theories \& Applications, Vol 7, No 2, 2017.

[8]. Jeng Lang Wu et al. "A Simultaneous Mixed LQR/H infinity Control Approach to the Design of Reliable Active Suspension Controllers" Asian Journal of Control, 2017.

[9]. Liu .et al. "Adaptive Sliding Fault Tolerant Control for Nonlinear Uncertain Active Suspension System" Journal of Franklin Vol. 353, p 180-199, 2016.

[10]. Bhowmik.A et al. "Adaptive Fault Tolerant Control for Active Suspension" IEEE First International Conference on Control, Measurement and Instrumentation, p 386-390, 2016.

[11]. L.C Felix Herran et al. "H2 Control of a One Quarter Semi-active Ground Vehicle Suspension” Journal of Applied Research and Technology, 2016. 